\title{
Erratum: Properties of the third harmonic of the radiation from self-amplified spontaneous emission free electron laser [Phys. Rev. ST Accel. Beams 9, 030702 (2006)]
}

\author{
E. L. Saldin, E. A. Schneidmiller, and M. V. Yurkov \\ (Received 14 December 2006; published 9 January 2007)
}

On page 030702-2 reference to Eq. (5) is incorrect. The correct referencing should be:

... Saturation length is well described in terms of the number of cooperating electrons $N_{\mathrm{c}}[13,23]$ :

$$
\hat{z}_{\mathrm{sat}} \simeq 3+\frac{1}{\sqrt{3}} \ln N_{\mathrm{c}} \text {. }
$$

Reference [23] should be added to the list of references:

[23] R. Bonifacio, L. De Salvo, P. Pierini, N. Piovella, and C. Pellegrini, Phys. Rev. Lett. 73, 70 (1994).

This erratum does not affect the conclusions. 